Pacific Journal of Mathematics

ORDER CONVERGENCE IN LINEAR TOPOLOGICAL SPACES 


\title{
ORDER CONVERGENCE IN LINEAR TOPOLOGICAL SPACES
}

\author{
RALPh E. DeMarR
}

If $L$ is a finite dimensional linear topological space (l.t.s.) over the reals, then it is easy to introduce a partial order into $L$ in such a way that convergence with respect to the topology is equivalent to order convergence (see definition below). This remark raises the following question: when can a locally convex l.t.s. $L$ over the reals be made into a partially ordered linear space in such a way that convergence with respect to the topology is equivalent to order convergence? In this paper we show that the answer to this question is: if and only if $L$ is a normed linear space. We emphasize, however, that we are referring to convergence of arbitrary nets. For convergence of sequences the above answer is not true; i.e., we will give an example of a partially ordered, locally convex l.t.s. $L$ having the property that convergence of sequences with respect to the topology is equivalent to order convergence.

In this paper we consider only real linear spaces with Hausdorff topologies. The reader will find a detailed discussion of partially ordered linear spaces and cones in such spaces in Chapter $1, \S 1$, of Namioka's memoir [2]. A general discussion of nets may be found in Chapter 2 of Kelley's book [1].

Definition 1. Let $L$ be a partially ordered linear space. A net $\left\{x_{n}, n \in D\right\}$ of elements from $L$ is said to order converge to 0 if and only if there exists a nonempty set $M \subset L$ which is directed to 0 such that for each $y \in M$ there exists $k \in D$ such that $-y \leqq x_{n} \leqq y$ for all $n>k$. A set $M \subset L$ is said to be directed to 0 if for each $y, z \in M$ there exists $u \in M$ such that $u \leqq y$ and $u \leqq z$, and if inf $M=0$. We say that inf $M=0$ if and only if $0 \leqq x$ for all $x \in M$ and $u \leqq x$ for all $x \in M$ implies that $u \leqq 0$. More generally, inf $M=y$ if and only if $\inf \{x-y: x \in M\}=0$ and $\sup M=y$ if and only if inf $\{y-x: x \in M\}=0$. A net $\left\{x_{n}, n \in D\right\}$ of elements from $L$ order converges to $x \in L$ if and only if the net $\left\{x_{n}-x, n \in D\right\}$ order converges to 0 .

Definition 2. A partially ordered, locally convex l.t.s. $L$ is called an $O$-space if convergence with respect to the topology is equivalent to order convergence. This refers, of course, to convergence of arbitrary nets.

Received April 15, 1963. 
Definition 3. A partially ordered, locally convex l.t.s. $L$ is called an $O S$-space if convergence of sequences with respect to the topology is equivalent to order convergence. (It is clear that every $O$-space is also an $O S$-space.)

THeOREM 1. If $L$ is a normed linear space, then $L$ can be partially ordered so that it becomes an O-space.

Proof. Let $u \in L$ be a fixed element such that $\|u\|=4$. Define the cone $K=\{\lambda(u+x): \lambda \geqq 0,\|x\| \leqq 1\}$ and then partially order $L$ as follows: $x \leqq y$ if and only if $y-x \in K$.

Now if $z \in L$ and $z \neq 0$, then $z+\|z\| \cdot u=\|z\|(u+z /\|z\|) \in K$; i.e., $-z \leqq\|z\| u$. Using $-z$ in place of $z$ we get $z \leqq\|z\| u$. Hence, $-\|z\| u \leqq z \leqq\|z\| u$, which is valid even if $z=0$. These latter inequalities state that norm convergence implies order convergence.

Now if $y=\lambda(u+x) \in K$, then $3 \lambda \leqq\|y\| \leqq 5 \lambda$. If we now take $y_{1}=\lambda_{1}\left(u+x_{1}\right) \in K$ and $y_{2}=\lambda_{2}\left(u+x_{2}\right) \in K$, then

$$
\begin{aligned}
\left\|y_{1}+y_{2}\right\| & =\left\|\left(\lambda_{1}+\lambda_{2}\right)\left(u+x_{1}\right)+\lambda_{2}\left(x_{2}-x_{1}\right)\right\| \\
& \geqq\left(\lambda_{1}+\lambda_{2}\right)\left\|u+x_{1}\right\|-\lambda_{2}\left\|x_{2}-x_{1}\right\| \\
& \geqq\left\|y_{1}\right\|+\lambda_{2} \geqq\left\|y_{1}\right\|+1 / 5\left\|y_{2}\right\| .
\end{aligned}
$$

Thus, we see that if $0 \leqq y \leqq z$, then

$$
\|y\|+1 / 5\|z-y\| \leqq\|z\| \text {. }
$$

This shows that the norm is monotone on the cone $K$.

In order to show that order convergence implies norm convergence, we must first show that if the set $M \subset L$ is directed to 0 , then inf $\{\|y\|: y \in M\}=0$. We do this by contradiction. Suppose $M$ is directed to 0 and $\inf \{\|y\|: y \in M\}=5 \alpha>0$. Let us select $z \in M$ such that $\|z\| \leqq 26 \alpha / 5$ and then define $M_{0}=\{y: y \in M$ and $y \leqq z\}$. Since we assume $\inf M=0$, we must have $\inf M_{0}=0$. From inequality (1) above, we see that if $y \in M_{0}$, then $1 / 5\|z-y\| \leqq\|z\|-\|y\| \leqq \alpha / 5$; i.e. $\|z-y\| \leqq \alpha$. Thus, if we define $w=z-\alpha u$, then for every $y \in M_{0}$ we have $y-w=\alpha[u+(y-z) / \alpha] \in K$, which means $w \leqq y$ for all $y \in M_{0}$. Since $\inf M_{0}=0$, we have $w \leqq 0$; i.e., $0 \leqq-w$. However, $\alpha u=z-w$ and $z \geqq 0$ implies that $4 \alpha=\|\alpha u\|=\|z+(-w)\| \geqq\|z\|$, which is a contradiction since $\|z\| \geqq 5 \alpha$. Hence, inf $\{\|y\|: y \in M\}=0$.

Now let $\left\{x_{n}, n \in D\right\}$ be a net which order converges to 0 . Thus, there must exist a set $M \subset L$ which is directed to 0 and which has the property that for each $y \in M$ there exists $k \in D$ such that $-y \leqq$ $x_{n} \leqq y$ for all $n>k$. Since inf $M=0$, we may find for each $\varepsilon>0$ an element $y \in M$ such that $\|y\|<\varepsilon / 3$. Hence, there exists $k \in D$ such 
that $-y \leqq x_{n} \leqq y$ for all $n>k$. Thus, $0 \leqq y-x_{n} \leqq 2 y$ and, hence, $\left\|x_{n}\right\|-\|y\| \leqq\left\|y-x_{n}\right\| \leqq 2\|y\|$; i.e., $\left\|x_{n}\right\| \leqq 3\|y\|<\varepsilon$. Thus, the given net norm converges to 0 .

It is interesting to note (without proof) two properties of $L$ when it is partially ordered as above. First, it is easy to show that the cone $K$ is a closed subset of $L$. Second, if $L$ is a Banach space, then it is conditionally Dedekind complete; i.e., if $M \subset L$ is directed by the partial ordering and is bounded above, then sup $M$ exists.

\section{Theorem 2. Every O-space $L$ is normable.}

Proof. If the $O$-space $L$ is not normable, then it can have no bounded convex neighborhood of 0 . We will show that this leads to a contradiction.

We first construct a directed set $D$ as follows: for each positive integer $\lambda$ and each convex neighborhood $U$ of 0 the triple $(\lambda, U, V)$ is formed, where $V$ is a convex neighborhood of 0 such that $V \subset U, V$ does not absorb $U$, and $V$ depends uniquely on $U$. We may always find such a $V$ for each $U$ since we are assuming that there is no bounded convex neighborhood of 0 . The directed set $D$ is the collection of all such triples with the partial ordering defined as follows: $\left(\lambda_{1}, U_{1}, V_{1}\right)<\left(\lambda_{2}, U_{2}, V_{2}\right)$ if and only if $U_{2} \subset U_{1}$ and $U_{1} \neq U_{2}$ or $U_{1}=U_{2}$ and $\lambda_{1}<\lambda_{2}$.

We now construct a net $\left\{\lambda x_{n}, n \in D\right\}$ as follows: for each $n=$ $(\lambda, U, V) \in D$ select $x_{n}$ so that $x_{n} \bar{\epsilon} V, \lambda x_{n} \in U$. This selection is possible because $V$ does not absorb $U$. It is clear that the above net converges to 0 with respect to the topology. Since $L$ is an $O$-space, the net must also order converge to 0 . This in turn implies that there exists $y \in L$ such that $0 \leqq y$ and that there exists $k=\left(\lambda_{0}, U_{0}, V_{0}\right) \in D$ such that $-y \leqq \lambda x_{n} \leqq y$ for all $n>k$. Now if we let $D_{0} \subset D$ consist of elements of the form $\left(\lambda, U_{0}, V_{0}\right)$, where $\lambda>\lambda_{0}$, then the inequalities $-y / \lambda \leqq x_{n} \leqq y / \lambda$ imply that the net $\left\{x_{n}, n \in D_{0}\right\}$ order converges to 0 . This follows from the fact that the sequence $\left\{y / \lambda: \lambda>\lambda_{0}\right\}$ converges to 0 with respect to the topology and, hence, order converges to 0 . Since $y \geqq 0$, we must have $\inf \left\{y / \lambda: \lambda>\lambda_{0}\right\}=0$. However, for $n \in D_{0}$ we see that $x_{n} \bar{\epsilon} V_{0}$ and, therefore, the net $\left\{x_{n}, n \in D_{0}\right\}$ does not converge to 0 with respect to the topology. Thus, we have a contradiction to our original assumption that there is no bounded convex neighborhood of 0 . Hence, $L$ is normable.

The contradiction obtained in the proof of Theorem 2 depended on the construction of an arbitrary net. The following example shows, however, that if we consider convergence of sequences only, then order convergence can in certain cases be equivalent to topological convergence in non-normable spaces. Let $\Omega$ be an arbitrary infinite set and let $L$ 
be the set of all real-valued functions defined on $\Omega$. If addition, multiplication by scalars, the partial order, and convergence are all defined pointwise, then it is easy to show that $L$ is an $O S$-space (see Definition 3). The essential thing here is that a convergent sequence must be bounded by some element in $L$. Since $\Omega$ is infinite, $L$ is not normable.

The above example leads to the following question: when is it possible to partially order a locally convex l.t.s. so that it becomes an OS-space? The answer (which the author is unable to supply) should provide an interesting classification of locally convex linear topological spaces.

\section{REFERENCES}

1. J. L. Kelley, General Topology, New York, 1955.

2. I. Namioka, Partially ordered linear topological spaces, Mem. Amer. Math. Soc. No. $24,1957$.

UNIVERSITY OF WASHINGTON 


\section{PACIFIC JOURNAL OF MATHEMATICS}

\section{EDITORS}

Robert Osserman

Stanford University

Stanford, California

M. G. Arsove

University of Washington

Seattle 5 , Washington
J. DugundjI

University of Southern Califorma: Los Angeles 7, California

Lowell J. Paige

University of California

Los Angeles 24, California

\section{ASSOCIATE EDITORS}

E. F. BECKENBACH

B. H. NeumanN

F. WOLF

K. YosIDA

\section{SUPPORTING INSTITUTIONS}

UNIVERSITY OF BRITISH COLUMBIA

CALIFORNIA INSTITUTE OF TECHNOLOGY

UNIVERSITY OF CALIFORNIA

MONTANA STATE UNIVERSITY

UNIVERSITY OF NEVADA

NEW MEXICO STATE UNIVERSITY

OREGON STATE UNIVERSITY

UNIVERSITY OF OREGON

OSAKA UNIVERSITY

UNIVERSITY OF SOUTHERN CALIFORNIA
STANFORD UNIVERSITY

UNIVERSITY OF TOKYO

UNIVERSITY OF UTAH

WASHINGTON STATE UNIVERSITY

UNIVERSITY OF WASHINGTON

AMERICAN MATHEMATICAL SOCIETY CALIFORNIA RESEARCH CORPORATION SPACE TECHNOLOGY LABORATORIES NAVAL ORDNANCE TEST STATION 


\section{Pacific Journal of Mathematics}

\section{Vol. 14, No. 1 \\ May, 1964}

Richard Arens, Normal form for a Pfaffian .........................

Charles Vernon Coffman, Non-linear differential equations on cones in Banach

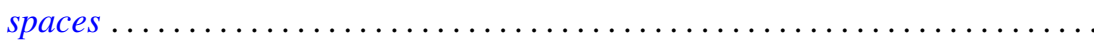

Ralph DeMarr, Order convergence in linear topological spaces ..............

Peter Larkin Duren, On the spectrum of a Toeplitz operator ................

Robert E. Edwards, Endomorphisms of function-spaces which leave stable all

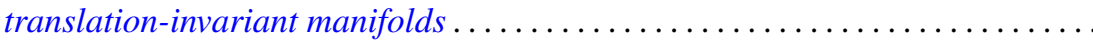

Erik Maurice Ellentuck, Infinite products of isols . . . . . . . . . . . . . . . . 49

William James Firey, Some applications of means of convex bodies . . . . . . . . 53

Haim Gaifman, Concerning measures on Boolean algebras ............. 61

Richard Carl Gilbert, Extremal spectral functions of a symmetric operator. . . . . . 75

Ronald Lewis Graham, On finite sums of reciprocals of distinct nth powers ..... 85

Hwa Suk Hahn, On the relative growth of differences of partition functions ...... 93

Isidore Isaac Hirschman, Jr., Extreme eigen values of Toeplitz forms associated

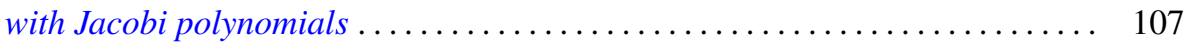

Chen-jung Hsu, Remarks on certain almost product spaces . . . . . . . . . . . 163

George Seth Innis, Jr., Some reproducing kernels for the unit disk . . . . . . . . . 177

Ronald Jacobowitz, Multiplicativity of the local Hilbert symbol . . . . . . . . . . . 187

Paul Joseph Kelly, On some mappings related to graphs ................. 191

William A. Kirk, On curvature of a metric space at a point . . . . . . . . . . . . 195

G. J. Kurowski, On the convergence of semi-discrete analytic functions . . . . . . . 199

Richard George Laatsch, Extensions of subadditive functions . . . . . . . . . . . 209

V. Marić, On some properties of solutions of $\Delta \psi+A\left(r^{2}\right) X \nabla \psi+C\left(r^{2}\right) \psi=0 \ldots 217$

William H. Mills, Polynomials with minimal value sets . . . . . . . . . . . 225

George James Minty, Jr., On the monotonicity of the gradient of a convex

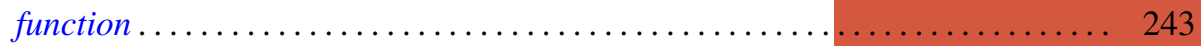

George James Minty, Jr., On the solvability of nonlinear functional equations of 'monotonic' type ................................... 249

J. B. Muskat, On the solvability of $x^{e} \equiv e(\bmod p) \ldots \ldots \ldots \ldots \ldots \ldots \ldots \ldots . \ldots \ldots$

Zeev Nehari, On an inequality of $P . R$. Bessack ................... 261

Raymond Moos Redheffer and Ernst Gabor Straus, Degenerate elliptic

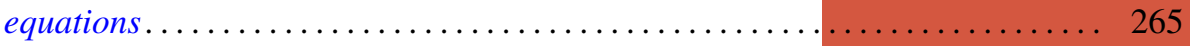

Abraham Robinson, On generalized limits and linear functionals . . . . . . . . . 269

Bernard W. Roos, On a class of singular second order differential equations with a

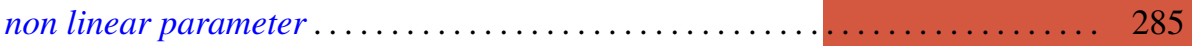

Tôru Saitô, Ordered completely regular semigroups . . . . . . . . . . . . . . . . 295

Edward Silverman, A problem of least area ....................... 309

Robert C. Sine, Spectral decomposition of a class of operators . . . . . . . . . 333

Jonathan Dean Swift, Chains and graphs of Ostrom planes . . . . . . . . . . . 353

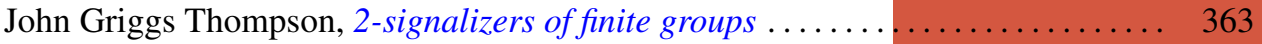

Harold Widom, On the spectrum of a Toeplitz operator . . . . . . . . . . . . . 365 